\title{
Obstruction is unimportant in the pathophysiology of hypertrophic cardiomyopathy
}

\author{
John Michael Criley ${ }^{1}$ and Robert James Siegel ${ }^{2}$
}

Departments of Medicine and Radiology, 'UCLA School of Medicine, Harbor-UCLA Medical Center, Torrance, California, and ${ }^{2}$ Cedars-Sinai Medical Center, Los Angeles, California, USA.

\begin{abstract}
Summary: There has been a longstanding controversy about the significance of intracavitary pressure gradients in hypertrophic cardiomyopathy (HCM). It has been generally assumed that the gradient is the result of an 'obstruction' that impedes left ventricular outflow and which can be relieved by operative intervention. In the first decade after the discovery of HCM (1957-66), the site of 'obstruction' was thought to be a muscular sphincter or contraction ring in the submitral region of the left ventricle, and operations designed to emulate pyloromyectomy (for hypertrophic pyloric stenosis) were developed. Following a challenge to the existence of the 'contraction ring' and an alternative non-obstructive explanation of the pressure gradient, the site of 'obstruction' was translocated to a point of apposition between the anterior mitral leaflet and the interventricular septum, a result of systolic anterior motion (SAM) of the mitral valve. Despite the translocation of the site and mechanism of 'obstruction', the operation for 'relief of obstruction' has not changed significantly. The newer site of 'obstruction' has been challenged on the grounds that the ventricle is not demonstrably impeded in its emptying; when a gradient is provoked, the ventricle empties more rapidly and more completely than it does without a gradient. In addition to a non-obstructive explanation of the gradient, other phenomena thought to be indicative of 'obstruction' can be explained by rapid and complete emptying of the ventricle (cavitary obliteration). Since the morbidity and mortality of symptomatic HCM patients without pressure gradients may exceed that of patients with pressure gradients, it is suggested that 'obstruction' may be unimportant in the pathophysiology of HCM and attention should be focused on abnormal diastolic function and life threatening arrhythmias.
\end{abstract}

\section{Introduction}

Hypertrophic cardiomyopathy (HCM) has been the subject of scepticism and controversy since its discovery (Brock, 1957) a quarter century ago. The initial scepticism about the very existence of the condition (Brock, 1959) was resolved when it became the subject of over 500 articles, an international symposium (Wolstenholme \& O'Connor (eds), 1964), and a comprehensive monograph (Braunwald et al., 1964) in less than a decade. There has been an unresolved controversy about the existence and importance of an obstruction, which may seem surprising when over forty appellations have been applied to this condition which contain the words 'stenosis' or 'obstructive' and at least six different surgical approaches to 'relief of obstruction' have been employed. The concept that an 'obstruction' was present was initially based on the recording of a pressure gradient in the left ventricular

Correspondence: J.M. Criley, M.D., Division of Cardiology, Harbor-UCLA Medical Center, 1000 Carson Street, Torrance, California 90509, USA. outflow trace (Brock, 1957, 1959) and the terms 'gradient' and 'obstruction' were equated (Brock, 1957, 1959; Wolstenholme \& O'Connor, 1964; Braunwald et al., 1964).

After two decades of intensive investigation, there has been a recent upsurge in articles questioning or refuting the significance or presence of 'obstruction' in HCM (Criley, 1979; Murgo, 1982; Goodwin, 1982; Canedo \& Frank, 1981; Shabetai, 1984; Sugrue et al., 1984). In addition to these challenges of the primacy of 'obstruction', there has been an increased interest in diastolic abnormalities in HCM (Gotsman \& Lewis, 1974; Sanderson et al., 1977; Lorell et al., 1982) as well as intensive studies on the prevalence and significance of life threatening arrhythmias (Savage et al., 1979; Maron et al., 1981; Krikler et al., 1980; Canedo et al., 1980; McKenna et al., 1981a,b). Disabling symptoms and the likelihood of sudden, unexpected death occur in patients with and without outflow tract gradients (Wynne \& Braunwald, 1984). Since symptomatic patients without pressure gradients may be at even 
greater risk for sudden death than those with gradients over $100 \mathrm{~mm} \mathrm{Hg}$ (Frank \& Braunwald, 1968), there is ample justification to support the concept that 'obstruction' may be unimportant in the pathophysiology of HCM.

It is the purpose of this communication to review the background of this ongoing controversy, and to attempt to clarify the confusion that exists over the mechanisms of non-obstructive pressure gradients. The following historical review of the decades after the discovery of HCM will provide the reader with a perspective from which to view the currently unresolved controversy.

\section{Historical review}

\section{The first decade}

The discovery and initial descriptions of HCM resulted from four dramatic characteristics of the disease: a murmur suggestive of aortic stenosis (Brock, 1957, 1959), a pressure gradient in the left ventricle thought to represent 'functional obstruction' (Brock, 1957, 1959; Wolstenholme \& O'Connor, 1964: Braunwald et al., 1964), inordinate and asymmetrical hypertrophy (Brock, 1957, 1959; Wolstenholme \& O'Connor, 1964; Braunwald et al., 1964; Teare, 1958), and the propensity for sudden and unexpected death in young individuals (Teare, 1958).

Effective operations were being developed for relief of valvar aortic stenosis, and it was logical to assume at that time that the pressure gradient represented an 'obstruction' which was responsible for the morbidity and mortality in HCM. Subsequently many surgical approaches were developed to relieve the 'obstruction', and dramatic intra-operative descriptions of the obstructing mechanism emerged. 'Forceful contraction of the outflow tract upon the examining finger is evident during systole' (Braunwald et al., 1964). 'That the obstruction is dynamic is immediately appreciated by the surgeon who passes his finger down through the obstruction in the beating heart ... compression around the finger is nothing short of painful' (Dobell $\&$ Scott, 1964). 'During systole, the musculature of the outflow tract contracted over a long segment, squeezing the operator's finger to a degree which could only be duplicated with some effort within the fist of the other hand' (Julian et al., 1965). This sphincter was described and illustrated as submitral in location (Brock, 1957, 1959; Braunwald et al., 1964; Dobell \& Scott, 1964; Julian et al., 1965). The most commonly performed operation, transaortic septal myotomymyectomy was designed to emulate pyloromotomy for hypertrophic pyloric stenosis (Braunwald et al., 1964).

An hourglass or conical narrowing of the left ventricle was demonstrated by selective angiocar- diography and was considered to be the angiographic analogue of the contraction ring (Braunwald et al., 1984; Bristow, 1965).

The existence of this obstructing sphincter was questioned by this author in 1965 when a significant dynamic systolic narrowing of the outflow tract was not seen by left ventriculography in patients with intracavitary pressure gradients - the hourglass 'systolic' narrowing of the left ventricle (Braunwald et al., 1964; Bristow, 1965) proved to be a diastolic event (Criley et al., 1965). When it was noted that the ventricle emptied more rapidly and more completely than the normal ventricle, and increased the rate and degree of emptying after a gradient was provoked or augmented by isoproterenol infusions, a non-obstructive mechanism for the pressure gradient and the alleged sphincter was proposed. It was suggested that rapid obliteration of the left ventricular cavity was responsible for the 'sphincter' and the pressure gradient (Criley et al., 1965).

Gauer (1950) and Gauer \& Henry (1964) had previously described non-obstructive intracavitary gradients in hyperkinetic, hypovolaemic ventricles. They demonstrated in animals subjected to haemorrhage or negative gravitational forces that intracavitary pressure gradients were present when the ventricle continues to contract after having expelled its pathologically small blood content'. Further studies on the mechanism of non-obstructive pressure gradients is our laboratory led us to conclude 'as the cavit becomes smaller, the body and the outflow tract of the $e^{+}$ ventricle become progressively isolated from one another, and a pressure difference develops between these two areas. These two regions are not separated by an obstruction, but by the tightly opposed walls of the essentially empty ventricle below. When the body of the ventricle is empty, the force is applied directly to the fluid (blood) trapped in the interstices, but is not transmitted to the outflow tract because the walls of the ventricle all of the way up to the outflow tract are approximated (White et al., 1967). Because we felt that this phenomenon was not comparable to Wigle's concept of 'catheter entrapment' (Wigle et al., 1966) we stated further 'it is important to point out that the catheter is not wedged or embedded in the myocardium when high pressures are recorded - these manœuvres will usually result in artefactual pressure waves' (Wigle et al., 1967) which were well described by Wigle et al. (1966).

There were three articles published at the end of the first decade that rebutted the non-obstructive concept and reaffirmed the presence and primacy of 'obstruction' (Wigle et al., 1966, 1967; Ross et al., 1966). However, the site of 'obstruction' was translocated from the aforementioned submitral muscular sphincter to an apposition of the anterior mitral leaflet and the interventricular septum which produced an 
angiographic 'lucent line' at the zone of contact (Ross et al., 1966). Since the inflow tract, or that portion of the ventricle immediately downstream from the mitral valve was said to never become obliterated (Ross et al., 1966), a recorded high pressure in this region was considered proof of an 'obstruction' in the outflow tract (Wigle et al., 1966, 1967; Ross et al., 1966).

The first decade after discovery thus ended in controversy. Investigators reached diametrically opposite conclusions. In the majority opinion, the HCM ventricle with a pressure gradient was impeded in its emptying by a zone of obstruction (Brock, 1957, 1959; Wolstenholme \& Connor, 1964; Braunwald et al., 1964; Bristow, 1965; Dobell \& Scott, 1964; Julian et al., 1965; Wigle et al., 1966, 1967; Ross et al., 1966), while a small minority held that a 'hypertrophic hyperkinetic cardiomyopathy' that emptied excessively rapidly (Criley et al., 1965; White et al., 1967), could produce the same pressure gradient without an obstruction.

\section{The second decade}

The controversy was seemingly resolved early in the second decade. The new site of 'obstruction', the zone of apposition of the anterior mitral leaflet and the interventricular septum which had been demonstrated by angiocardiography (Simon et al., 1967; Dinsmore et al., 1966) was also demonstrated by M-mode echocardiography (Shah et al., 1969). It was proposed that, since the obstruction was now 'mitrogenic', mitral valve replacement was the treatment of choice in patients with large resting pressure gradients (Cooley et al., 1973). Later in the second decade, Mmode and 2-dimensional echocardiography further solidified the case for mitrogenic obstruction: systolic anterior motion (SAM) of the mitral valve could be correlated with the presence and magnitude of the pressure gradient (Henry et al., 1973) and echocardiographic demonstration of premature closure of the aortic valve furnished further proof of a late systolic cessation of flow presumably because of obstruction (Feizi \& Emanuel, 1975).

\section{The third decade}

The third, or current decade has brought a resurgence of articles questioning or refuting the presence of obstruction in HCM (Criley, 1979; Murgo, 1982; Goodwin, 1982; Canedo \& Frank, 1981; Shabetai, 1984; Sugrue et al., 1984). The efficacy of operations for 'relief of obstruction' has been questioned on the basis of high operative mortality and failure to reduce the incidence of sudden death (Canedo \& Frank, 1981; Nishimura et al., 1983). However, several groups have continued to recommend septal myectomy as a treatment of choice for symptomatic patients with high pressure gradients (Maron et al., 1983; Rothlin et al., 1983). Because the operation usually abolishes the pressure gradient and concurrently improves the symptomatic status of the patient at least one functional class, the results of the operation have been used as further proof that 'obstruction' is of primary significance. However, unlike the operative relief of valvar aortic stenosis, in which the left ventricular ejection fraction often rises, in HCM, the ejection fraction usually falls (Borer et al., 1979). Despite the translocation of the 'obstruction' from a muscular sphincter to SAM-septal contact, the most commonly used surgical approach has remained unchanged - an analogue to pyloric myotomy (Braunwald et al., 1964; Ross et al., 1966; Morrow et al., 1975).

The essence of the case for obstruction is illustrated in Figure 1. Although the rapid and complete emptying of the ventricle is conceded by advocates of obstruction (Pollick et al., 1982, 1984), the characteristic pressure/flow relationships (Braunwald et al., 1984; Ross et al., 1966) are used to sustain the concept that the ventricle is nevertheless impeded in its emptying. The systolic ejection period can be divided into three time periods: an early period of high flow and minimal gradient, a middle period of rising gradient and declining flow, and a late period of no flow with a persistent gradient. When hydrodynamic formulae are applied to the instantaneous pressure/flow relationships, the calculated outflow orifice is normal in the first part of systole, declines rapidly in the middle period and approaches zero in late systole (Braunwald et al., 1964). Since SAM-septal contact (SSC, Figure 1) occurs in the middle period (Pollick et al., 1982, 1984), a strong case for obstruction (emptying impeded by SAM and a pressure gradient) has been established.

\section{The non-obstructive concept - a status report}

\section{The rate of ventricular emptying}

One of the major arguments used to question the presence and significance of the 'contraction ring obstruction' can be applied to the new site of obstruction as well - the HCM ventricle empties more rapidly and more completely than the normal ventricle (Wilson et al., 1967; Murgo et al., 1980). A ventricle obstructed by aortic stenosis empties more slowly than the normal ventricle (Wilson et al., 1967).

When ventricular volumetric data are correlated with the pressure and flow data in Figure 1, an alternative non-obstructive explanation for their relationships can be invoked. The solid circles represent a typical ventricular HCM emptying curve obtained from a patient with a $100 \mathrm{~mm} \mathrm{Hg}$ intracavitary pressure gradient and trivial $(<1+)$ mitral regurgitation, and the open circles represent a normal patient with 


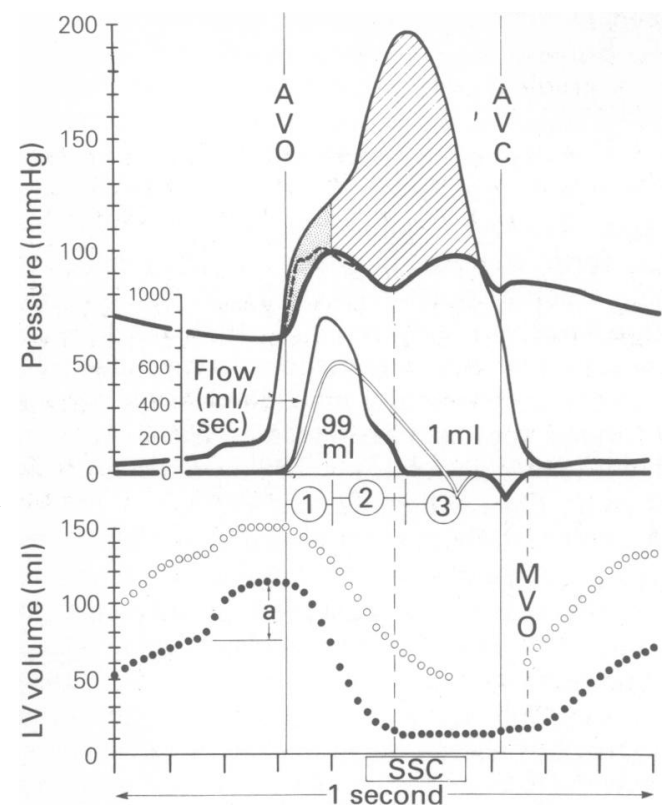

Figure 1 Typical haemodynamic and volumetric findings in HCM. Left ventricular (LV), aortic (Ao) pressure, aortic flow, and left ventricular volumetric relationships are displayed. Vertical solid lines indicate aortic valve opening (AVO) and aortic valve closure (AVC), and encompass the systolic ejection period. The dashed vertical lines indicate the midpoint of systole and mitral valve opening (MVO). The pressure gradient (hatched area) reaches maximum magnitude in the last half of systole. The aortic flow in HCM (black curve) is maximal in the first half of systole, with greater peak flow acceleration and velocity than normal (white curve). Correspondingly, the rate of $\mathrm{LV}$ ejection, as reflected in the emptying slope of the LV volumetric curve $(O)$, is more rapid than normal $(\mathrm{O})$. The systolic pressure and flow relationships are divided into three phases. During phase 1 , peak flow is achieved while an impulse gradient (shaded area) develops between the LV body, outflow tract (interrupted line) and aortic pressure. In phase 2, flow decelerates to nil while the gradient increases and the LV volume approaches a minuscule residual volume. Mitral valve apposition with the interventricular septum, or SAM-septal contact (SSC) occurs during phase 2 and extends into phase 3 . In phase 3 aortic outflow has ceased and LV pressure and the gradient decline. During diastole, there is a large atrial systolic contribution to LV filling (a) in HCM. (Reproduced from Circulation, 1985, 72, 1150 with permission from the American Heart Association).

excellent ventricular function (ejection fraction, $70 \%$ ) for comparison. In the first half of systole, over $90 \%$ of the ventricular contents are ejected and the residual volume is about $10 \mathrm{ml}$. The ventricle rapidly eliminates its contents, leaving only a 'dead space' consisting of the non-contracting aortic vestibule and the vase, or inflow tract of the ventricle, in which the crowded mitral apparatus is enclosed. In the last part of systole, the empty ventricle continues to squeeze isovolumetrically on its pathologically small residual contents, maintaining a pressure gradient in the absence of volumetrically measured flow (Braunwald et al., 1964; Murgo, 1982; Wilson et al., 1967; Murgo et al., 1980; Siegel \& Criley, 1985).

Thus the ventricle begins systole with a wide communication (and a small pressure gradient) between the body and outflow tract (Figure 1, phase 1) and ends with a virtually empty ventricle 'gumming' on its meagre contents (phase 3 ). In the mid-systolic time period (phase 2), the body and outflow tract pressures become progressively disparate as the body approaches total elimination of its contents and discontinuity of its vanishing lumen with that of the outflow tract. The continued rapid rate of emptying and the pathologically small residual volume achieved during this period belie the sudden imposition of an 'obstruction'. The ventricle can be said to be exerting force in excess of that which is needed to empty the ventricle, and that excessive applied force and not an interposed 'obstruction' results in the pressure gradient.

A comparison of emptying in the same ventricle with and without a pressure gradient

The ability of the HCM ventricle to empty more rapidly and more completely than the normal ventricle would appear to refute the presence of a zone of 'obstruction', which by definition is an impediment or hindrance to passage. In contrast to HCM, there is a negative correlation between the magnitude of the pressure gradient and the rate of ventricular emptying in valvar aortic stenosis (Wilson et al., 1967). However, the ability of the HCM ventricle to empty rapidly despite a pressure gradient might be explained if one or both of the following factors is invoked: the HCM ventricle is strong enough to overcome the hindrance to maintain a rapid ejection despite its presence and/or mitral regurgitation permits emptying of the 'obstructed' ventricle through an alternate orifice. Therefore, comparing the emptying rate of HCM ventricles with normal ventricles may not be appropriate. Although Murgo et al. (1980) found that the presence or absence of mitral regurgitation in HCM subjects did not affect the rapid rate of ventricular emptying, the possibility that a superhuman ventricle can empty faster than a normal ventricle despite the handicap of an 'obstruction' cannot be discounted when comparing different patient groups.

For this reason, we undertook the study of the rate of ventricular emptying with and without induced 

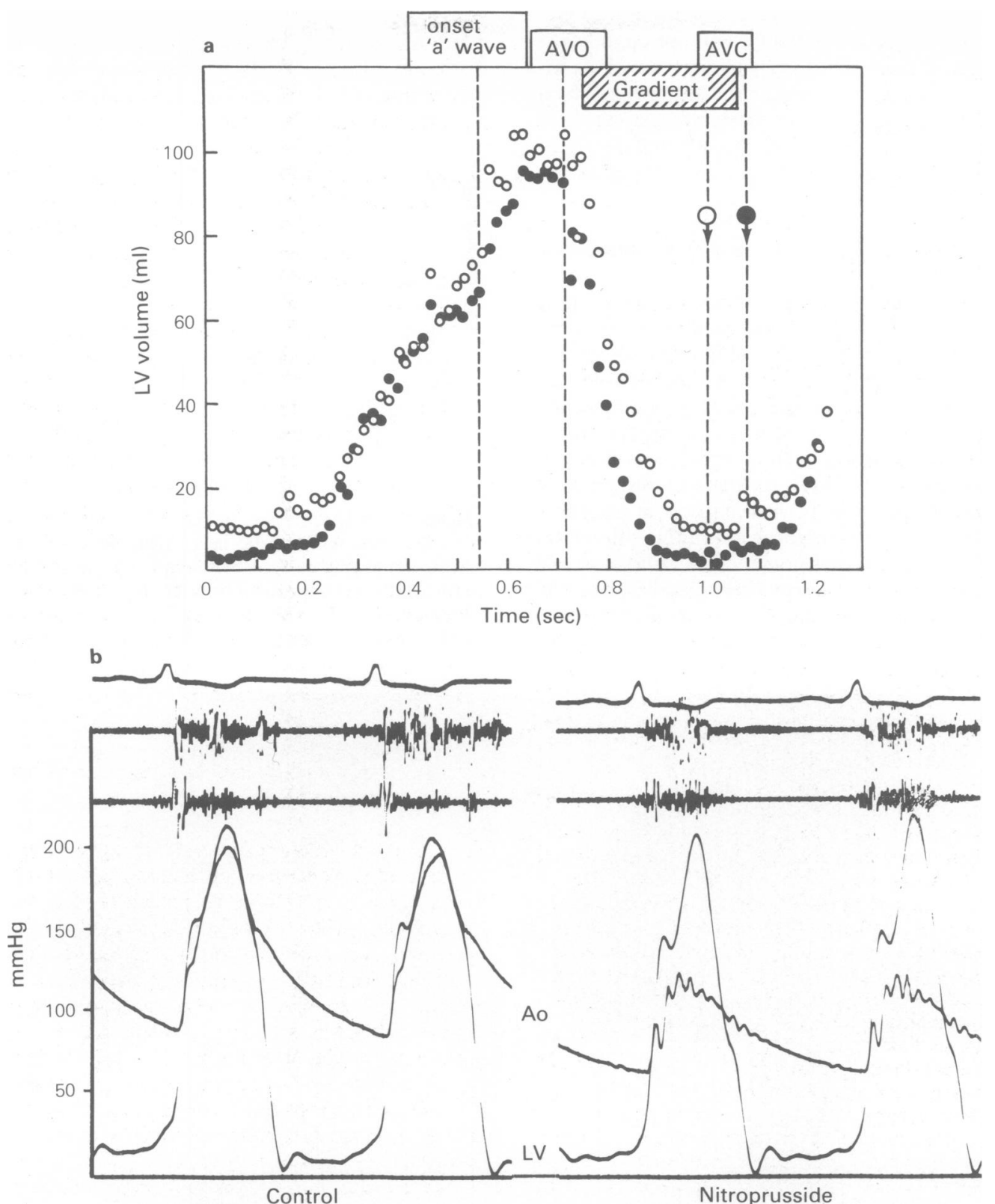

Control

Nitroprusside

Figure 2 Comparison of ventricular emptying before and after the provocation of a pressure gradient. During the control period (b, left) the patient was uncharacteristically hypertensive and had a trivial gradient. During a sodium nitroprusside infusion, a pressure gradient of $87 \mathrm{~mm} \mathrm{Hg}$ develops (b, right) as the aortic pressure falls to normal and the left ventricular pressure and heart rate remain constant. The angiographic frame by frame volumes are indicated by during the presence of the pressure gradient and by $O$ in the absence of the gradient. The timing of aortic valve closure is indicated by the large dot symbols and dashed lines under AVC. The left ventricle empties more rapidly and completely when the gradient is present (ejection fraction increases from 89 to $94 \%$ ) and the minimum systolic volume of $5 \mathrm{ml}$ is reached well before aortic valve closure. The prolongation of the systolic ejection period during the presence of a gradient results from prolonged LV isovolumetric contraction and delayed relaxation. The onset of SAM-septal contact while the gradient was present is indicated by the arrow. (Reproduced with permission from British Heart Journal, 1985, 53, 285.) 
pressure gradients in patients without significant mitral regurgitation. Thus each patient served as his own control. Whether the gradient was provoked by a vasodilator (Figure 2) or a postextrasystolic beat phenomenon (Figures 3 and 4), the rate and degree of emptying were enhanced in the presence of a gradient (Siegel \& Criley, 1985).

\section{Systolic anterior motion (SAM) and cavity obliteration}

The mitral valve sleeve is invaginated into the cavity of the base of the left ventricle, and occupies most of the space within it during diastole (Figure 5). When the ventricle eliminates its contents during systole, the mitral valve becomes a space-occupying structure which forms the boundary between the hypercontractile, obliterating portion of the ventricle and the noncontractile aortic vestibule. As the circumference of the contractile portions of the ventricle is markedly reduced, as seen in the angiocardiographic silhouettes in Figure 4 and 2-dimensional echocardiograms in Figure 5, the mitral valve sleeve becomes distorted and pleated along its long axis as its available space becomes constricted. The fluted valve somewhat re-

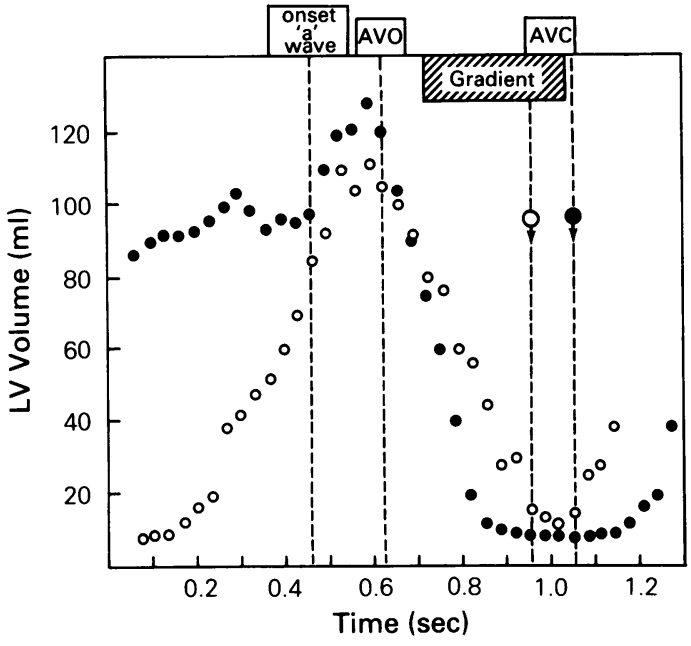

Figure 3 Augmentation of left ventricular emptying during a postextrasystolic beat. Volumetric curves indicate more rapid and complete emptying during the beat with a $110 \mathrm{~mm} \mathrm{Hg}$ gradient between the left ventricle and femoral artery. Format similar to Figure 2. (Reproduced with permission from British Heart Journal, 1985, 53, 287.)

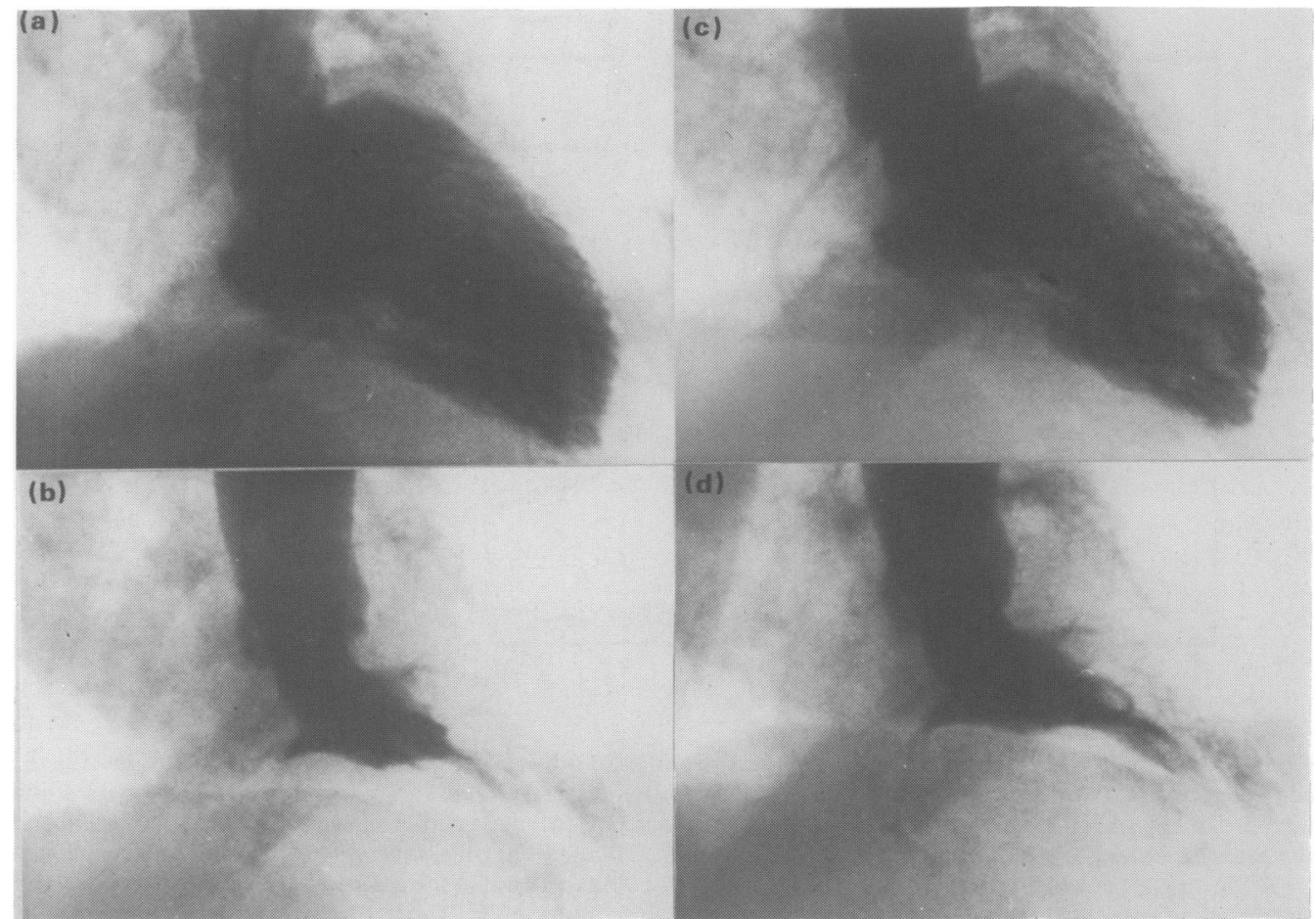

Figure 4 Angiographic demonstration of augmented emptying during a postextrasystolic beat. The $110 \mathrm{~mm} \mathrm{Hg}$ gradient postextrasystolic beat in the patient illustrated in Figure 3 is demonstrated at end diastole (a) and end systole (b). The control (no gradient) beat is shown in diastole (c) and systole (d). Although the ejection fraction is supernormal during the control beat, the ventricle empties more completely in the gradient cycle. (Reproduced with permission from British Heart Journal, 1985, 53, 288.) 


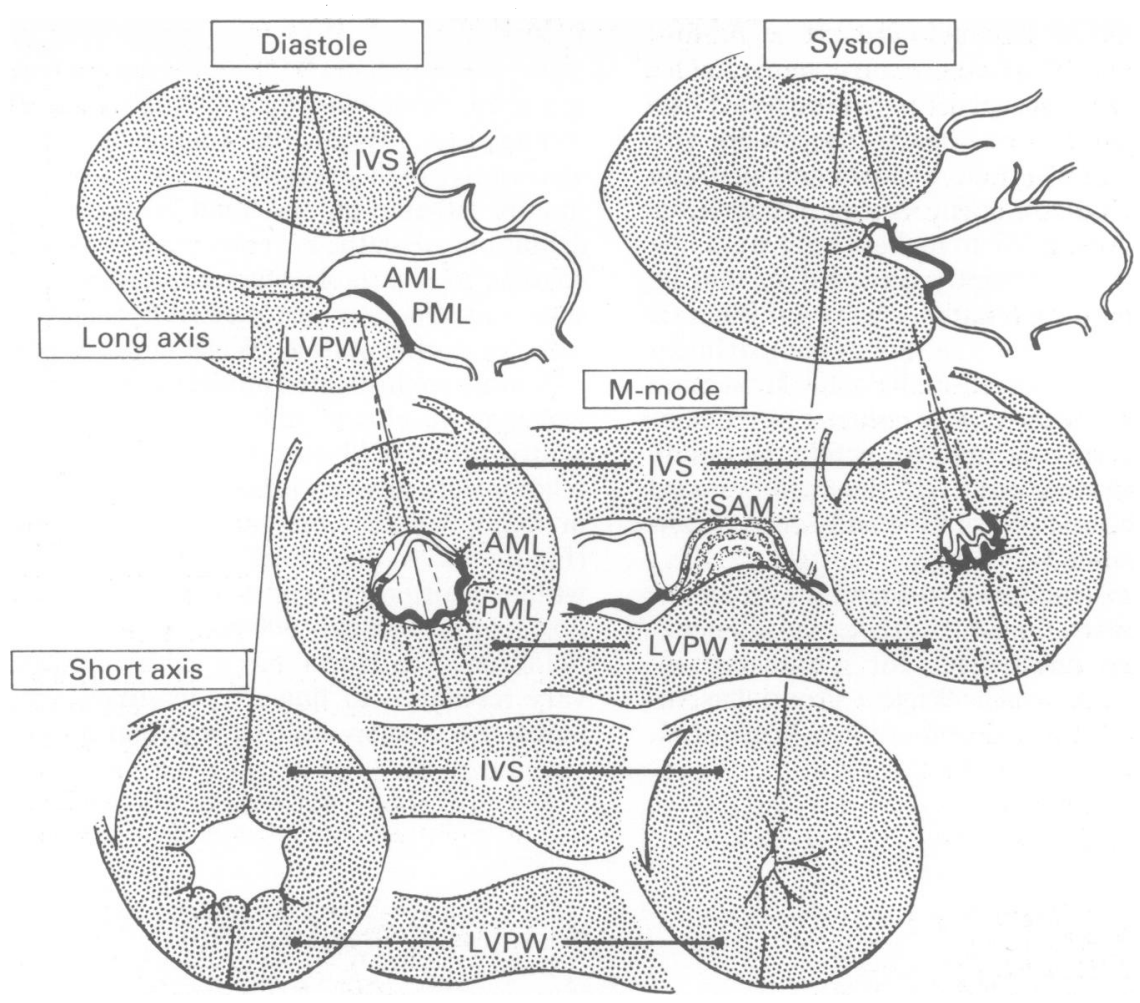

Figure 5 Echocardiographic depiction of systolic anterior motion (SAM) resulting from cavitary obliteration. Parasternal long axis (top row) and short axis 2 dimensional echocardiographic views of the HCM ventricle are correlated with M-mode echoes depicting SAM (centre) and obliteration of the submitral cavity (bottom centre). The anterior mitral leaflet (AML) is depicted in white, and the posterior mitral leaflet (PML) in black. Divergence of the ultrasound beam results in a depiction of both leaflets of the corrugated valve apparatus as a multi-layer laminated structure in the M-mode echocardiogram (centre). LVPW = left ventricular posterior wall, IVS =interventricular septum. (Reproduced from Circulation, 1985, 72, 1152, with permission from the American Heart Association.)

sembles a collapsed umbrella in a short axis cross sectional view (centre right, Figure 5).

The M-mode echocardiogram through the base of the ventricle (centre, Figure 4) depicts a sessile septum, a hyperactive posterior left ventricular wall and the mitral valve 'sandwiched' between. The obliteration of the left ventricular cavity up to and including the submitral apparatus causes the puckering demonstrated in the 2-dimensional echocardiogram and apposition of portions of both leaflets of the mitral valve with the septum. Rather than representing an 'obstruction', the mitral apparatus can form the bottom of the left ventricular dead space that remains after its contents are eliminated. SAM may also comprise the submitral apparatus (Goodwin, 1982; Sahn et al., 1982) in the obliterated cavity. The inflow tract immediately apical from the mitral valve is obliterated (Ginzton \& Criley, 1981).
Echocardiographic support for the non-obstructive nature of SAM results from the demonstration of typical echocardiographic SAM in patients with pressure gradients due to cavity obliteration (Ginzton \& Criley, 1981) and more recent studies in our laboratory demonstrating that the duration of SAM-septal contact is directly related to the degree of hypercontractility as measured by percent fractional shortening. The 'lucent line' deformity of the mitral valve is seen in experimental animals with induced pressure gradients (Criley et al., 1976) - further evidence that SAM may merely represent crowding and distortion of the mitral apparatus in the pathologically small ventricle and not 'obstruction'.

Pressure gradients and cavity obliteration

The physical basis for non-obstructive pressure 
gradients due to cavitary obliteration can be demonstrated in a simple hydrodynamic caricature (Figure 6). Two catheters are inserted through the open cuff of a fluid filled surgical glove, one in the thumb (representing the obliterating body), the other in the palm (representing a compliant aortic vascular bed). After twisting the cuff of the glove to make it watertight, the thumb of the glove is abruptly squeezed so that its contents are rapidly eliminated. A jet of water is ejected from the catheter in the thumb compartment and a trickle from the catheter in the palm. If pressure is recorded (Figure 6, centre) with catheter micromanometers, there is a pressure gradient within the thumb between the obliterating body and the uncompressed base of the thumb, analogues of the body and outflow tract of the left ventricle.

This model can also be used to depict the difference between cavity obliteration and 'catheter entrapment', a non-obstructive mechanism for producing intracavitary gradients which Wigle's group has incorrectly equated with cavity obliteration (Wigle et al.,
1966; Borer et al., 1979). To produce 'catheter entrapment' the thumb of the glove can be emptied and then prevented from filling by maintaining a slight external compression. When the thumb is then squeezed vigorously, high pressure can be recorded from the thumb catheter but no fluid is ejected. In Wigle's definition of catheter entrapment, the manometer records 'to a variable degree, endocardial tissue pressure and blood is not ejected from the entrapped catheter during systole (Wigle et al., 1966).

A more sophisticated model of cavitary obliteration which more closely resembles the hyperkinetic left ventricle of HCM can be constructed to study the relationship between pressure gradients and changes in filling volume, resistance, and contractile force (Figure 7). A fluid filled latex 'ventricle' is placed within an airtight plastic box, and air is pulsed into the box at approximately $300 \mathrm{~mm} \mathrm{Hg}$ to provide "contractile force'. The 'aorta' has a calibrated constrictor to vary resistance to flow. To maintain simplicity, no valves are used so that the ventricle empties into and

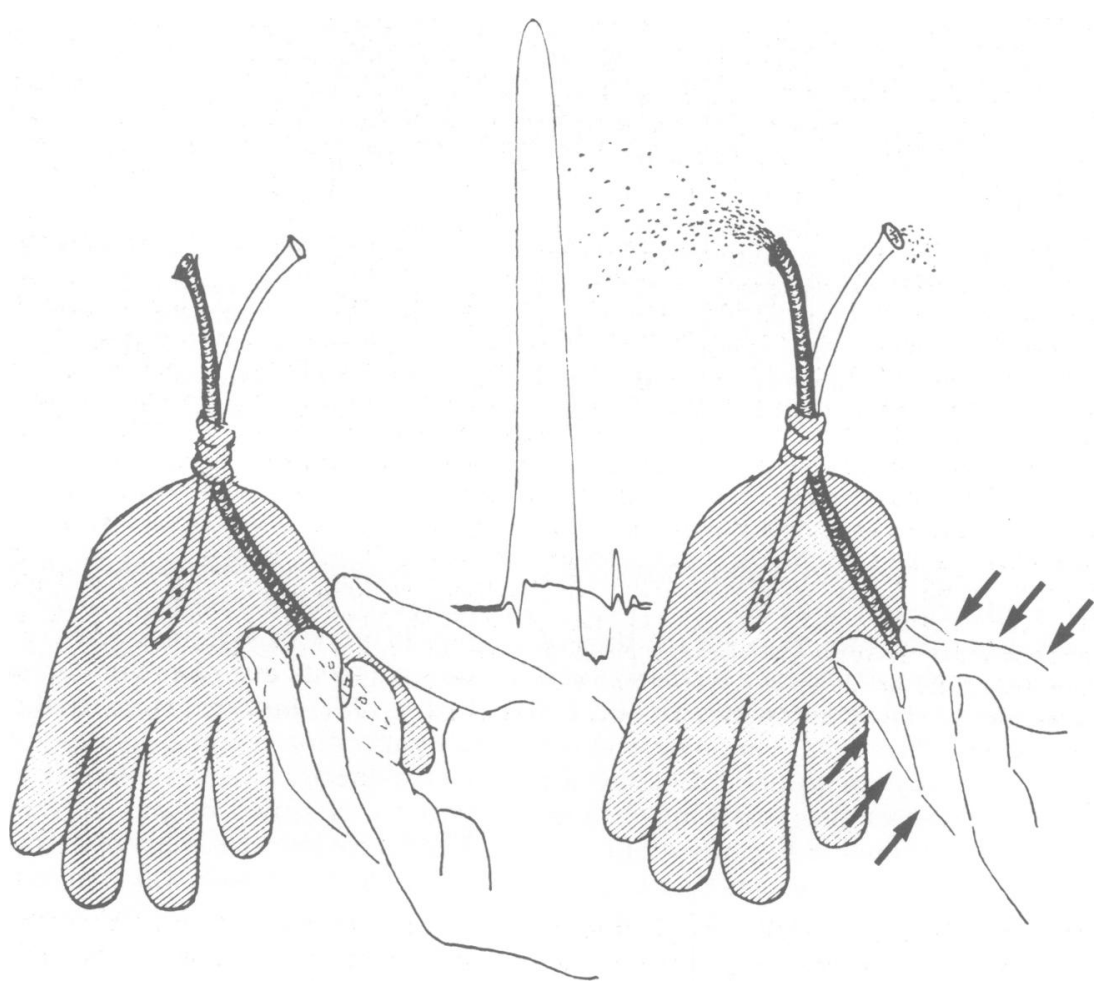

Figure 6 Pressure gradients due to cavitary obliteration - a simple model. A rubber glove containing 2 catheters has been filled with water and the thumb is rapidly compressed, resulting in rapid emptying of the thumb (the analogue of the body of the left ventricle) and expulsion of fluid through the lumen of the catheter. Pressures (centre) recorded from that location with a catheter micromanometer reveal a higher pressure in the thumb (ventricular body) than in the palm ('outflow tract'). 


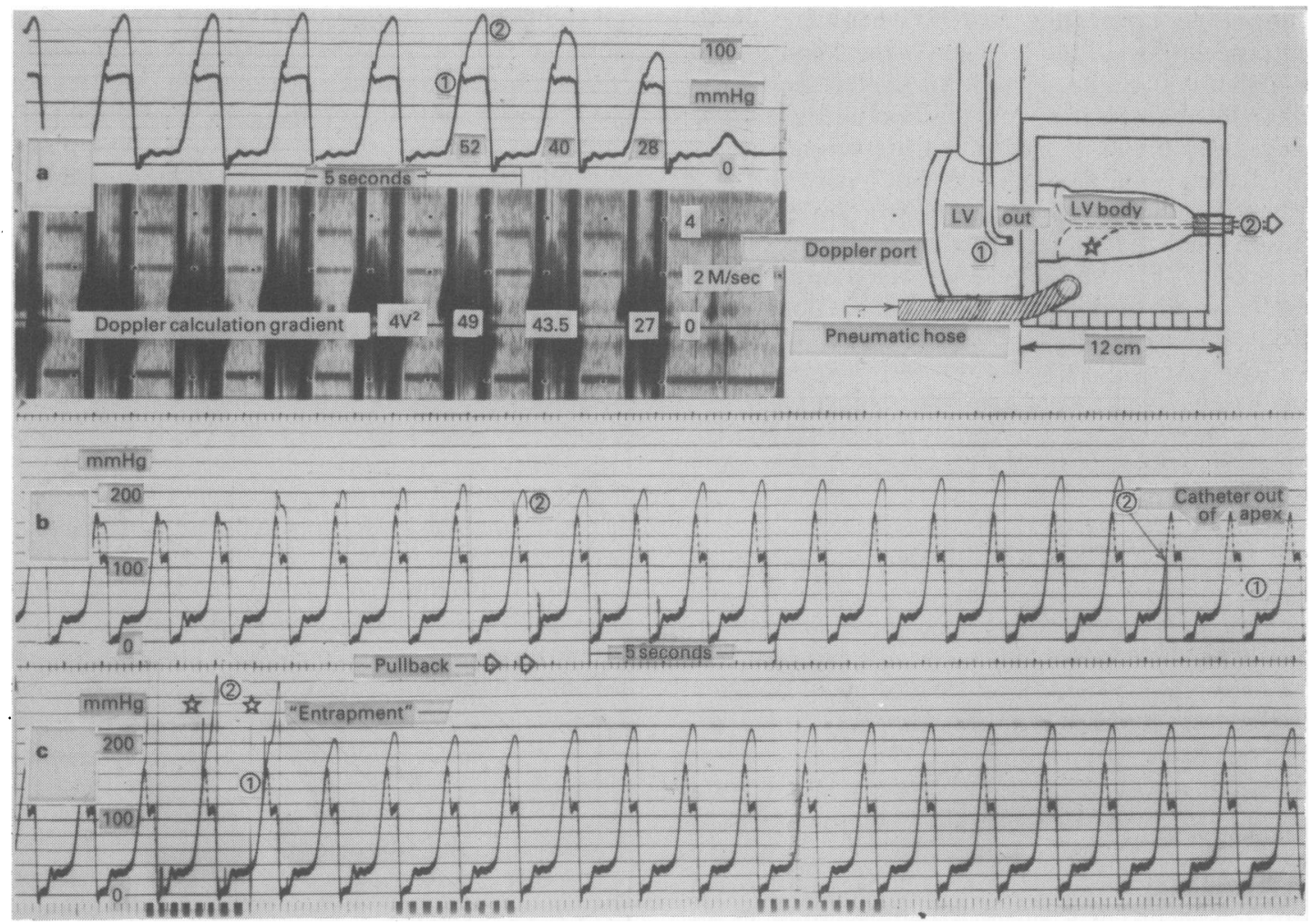

Figure 7 Hydrodynamic model of cavitary obliteration. A conical latex ventricle, suspended in an airtight plastic box is caused to empty by application of pneumatic pressure to the interior of the box. Complete emptying obliterates the cavity of the LV body up to the level of the outflow tract (LV out), which is prevented from collapsing by attachment to a rigid collar. The systolic shape of the ventricle (determined by cineangiography) is indicated by the dashed lines. (a) Intracavitary micromanometer pressures recorded during a diminishing pressure gradient (caused by decreasing external pneumatic pressure) are compared with continuous wave Doppler flow velocity recordings. The modified Bernoulli equation, pressure gradient $=4 \times$ velocity $^{2}$, indicates a close correlation of calculated and measured pressure gradients due to cavitary obliteration. (b) A retrograde micromanometer catheter (1) remains in the outflow tract while a continuous catheter withdrawal through the entire ventricle of an apically inserted catheter (2) is recorded. The pressure is uniformly high when the catheter is withdrawn into and through the obliterated cavity, and drops abruptly to atmospheric pressure as it emerges from the external apical fitting. (c) 'Catheter entrapment' is contrasted with cavitary obliteration. The apical catheter (2) has been advanced into the wall of the ventricle (star, 7a) where a spuriously high $300 \mathrm{~mm} \mathrm{Hg}$ pressure is recorded from the entrapped pressure sensor and delayed pressure downstrokes are recorded (stars, 7c). Withdrawal of the catheter from this position into the obliterated cavity of the body of the latex ventricle demonstrates an abrupt decline to a $200-220 \mathrm{~mm} \mathrm{Hg}$ pressure without a delayed downstroke. There is a $100 \mathrm{~mm} \mathrm{Hg}$ gradient due to cavitary obliteration.

fills from the aorta. In this model, non-obstructive gradients can be provoked by reducing filling volume and/or aortic resistance, or by increasing the contractile force to induce obliteration of the cavity. Outflow tract continuous wave Doppler flow velocity signals can be recorded while varying the pressure gradient, and these Doppler signals track with the gradient (Figure 7a), since the gradients are not artefactual.
The pressure transition within the ventricle $(7 \mathrm{~b})$ occurs at the interface between the obliterated body and patent outflow region ('dead space'), with the latter prevented from collapse by its attachment to a rigid collar within the box.

Spuriously high pressures due to "catheter entrapment' can also be generated when the catheter is advanced into the wall of the latex ventricle (star, 
Figure 7a). The pressures recorded when the catheter is entrapped (stars, Figure 7c) are higher than that in the obliterated cavity, change in magnitude as the catheter is manipulated, and decline later than the intracavitary pressure. Unlike the pressure gradients with cavitary obliteration, fluid is not ejected through the lumen of the entrapped catheter recording high pressure and the pressure difference between the entrapped catheter and the outflow tract intracavitary pressure cannot be predicted from Doppler flow velocity.

\section{Miscellaneous manifestations of 'obstruction': the} murmur, the Valsalva response, the post-extrasystolic beat, the carotid pulse, the apical impulse, the systolic ejection period

The 'obstructive' concept of HCM is well ingrained because so many phenomena associated with the condition have traditionally been considered manifestations of an obstruction. However, the evidence that these cardinal manifestations are a result of obstruction remains circumstantial. Furthermore, there are many significant dissociations between these manifestations and quantitative measurements of pressure gradients which should be considered. Some of these paradoxes will be briefly discussed.

The characteristic mid-late systolic murmur of HCM is considered a cardinal manifestation of an outflow tract stenosis, but there are a number of observations which do not fit this concept (Kramer $e t$ al., 1986). The murmur may be present in the absence of a gradient and the magnitude of the murmur does not always track with the magnitude of the gradient, as demonstrated in Figures 8 and 9. The murmur is best heard at the apex and lower sternal border, and rarely transmitted to the base and carotid arteries unlike other murmurs generated in the outflow tract. Intraoperatively, a thrill is felt over the left atrium, but not the outflow tract and aorta (Julian et al., 1965). The mid-late systolic murmur is recorded in the left atrium by intracardiac phonocardiography, while a typical 'ejection murmur', peaking in early systole, is recorded during the rapid ejection phase of systole in the aortic roof (Criley et al., 1976). Each of these observations suggests that the principal murmur is caused by mitral regurgitation through the distorted mitral valve. The response of the murmur to postural manoeuvres is identical to that of the murmur of mitral prolapse because both HCM and mitral prolapse have a significant ventriculo-valvular disproportion in which the ventricle is too small to support the mitral valve in a position of function in mid and late systole. Mitral regurgitant murmurs can be heard at the base as a result of a basally directed jet, emulating outflow tract murmurs.

The immediate rise in left ventricular pressure and intraventricular pressure gradient with the strain phase of the Valsalva manoeuvre has been cited as evidence of true obstruction, since it would be necessary to postulate that during this manoeuvre an immediate increase in contractile force takes place in essentially empty portions of the ventricular cavity' if cavity obliteration was responsible for the response (Ross et al., 1966). An examination of the haemodynamic response to the strain phase (Figure 9) reveals that the left ventricular pressure rises immediately (as does the aortic pressure) because of the upward offset of the pressure pulse caused by the increase in intrathoracic pressure - the developed left ventricular pressure is unchanged. As the ventricular input progressively declines, diminishing output leads to a decline in aortic pressure. It should also be noted that the murmur intensity declines in the beat which has the largest gradient (arrow, Figure 9).

The Brockenbrough-Braunwald-Morrow phenomenon (Brockenbrough et al., 1961), or failure of the postextrasystolic arterial pulse pressure to rise (Figure 8 b) has also been attributed to increased 'obstruction'. Since the rapidity and degree of emptying are enhanced, rather than retarded in the beat with a gradient (Siegel \& Criley, 1985; Rackley et al., 1966) (Figures 3 and 4), three non-obstructive mechanisms can be invoked for the attenuation of the arterial pulse pressure: (1) reduced diastolic left ventricular com- 8 pliance preventing increased filling during the post extrasystolic pause, (2) an emptier, more compliant aortic bed as a result of prolonged runoff, and (3) increased mitral regurgitation due to earlier and more profound distortion of the mitral apparatus in the inotropically stimulated ventricle.

The characteristic 'spike and dome' contour of the carotid pulse and 'triple ripple' of the apical impulse can be readily explained on the basis of cavitary obliteration. The carotid 'spike' represents the rapid ejection of blood in the first third of systole and the 'dome' a reflected wave from the peripheral reflecting sites (and not a second 'obstructed' ejection). The $a$ wave of the apical impulse is a reflection of the incompliant ventricle, and the late systolic wave following the $e$ point results from late systolic isometric contraction in the emptied ventricle. The prolongation of the systolic ejection period, as defined by the delayed dicrotic notch of the carotid pulse does not actually measure prolonged ejection, but rather continued isometric contraction and delayed relaxation of the ventricle after rapid ejection has taken place (Figures 1-3). The time required for the HCM ventricle to empty is shorter and the rate of ejection is more rapid than normal (Wilson et al., 1967; Murgo et al., 1980). Early systolic closure of the aortic valve is also considered a manifestation of obstruction (Feizi \& Emanuel, 1975), but it could also result from rapid emptying(Wilson et al., 1967; Murgo et al., 1980) since 
a

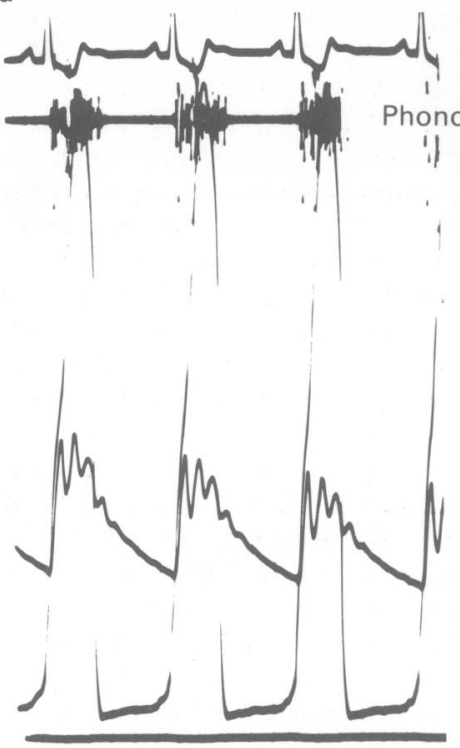

$<1 \mathrm{sec}>$

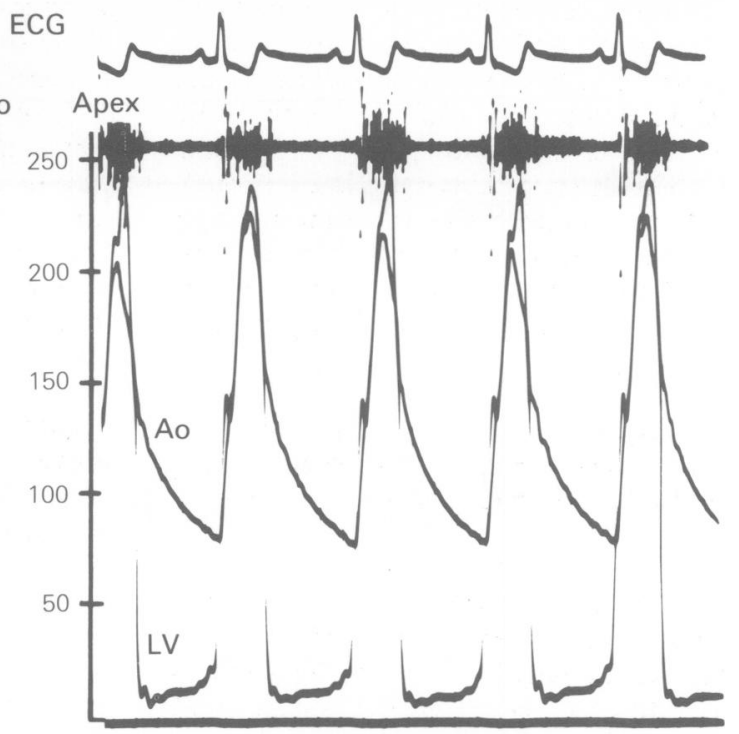

Methoxamine

Figure 8 The relationship of the magnitude of the murmur and pressure gradient in HCM; a comparison with valvar aortic stenosis. (a) An HCM patient with a gradient of over $150 \mathrm{~mm} \mathrm{Hg}$ has the gradient abolished with an infusion of methoxamine (right), and the murmur magnitude is unchanged.

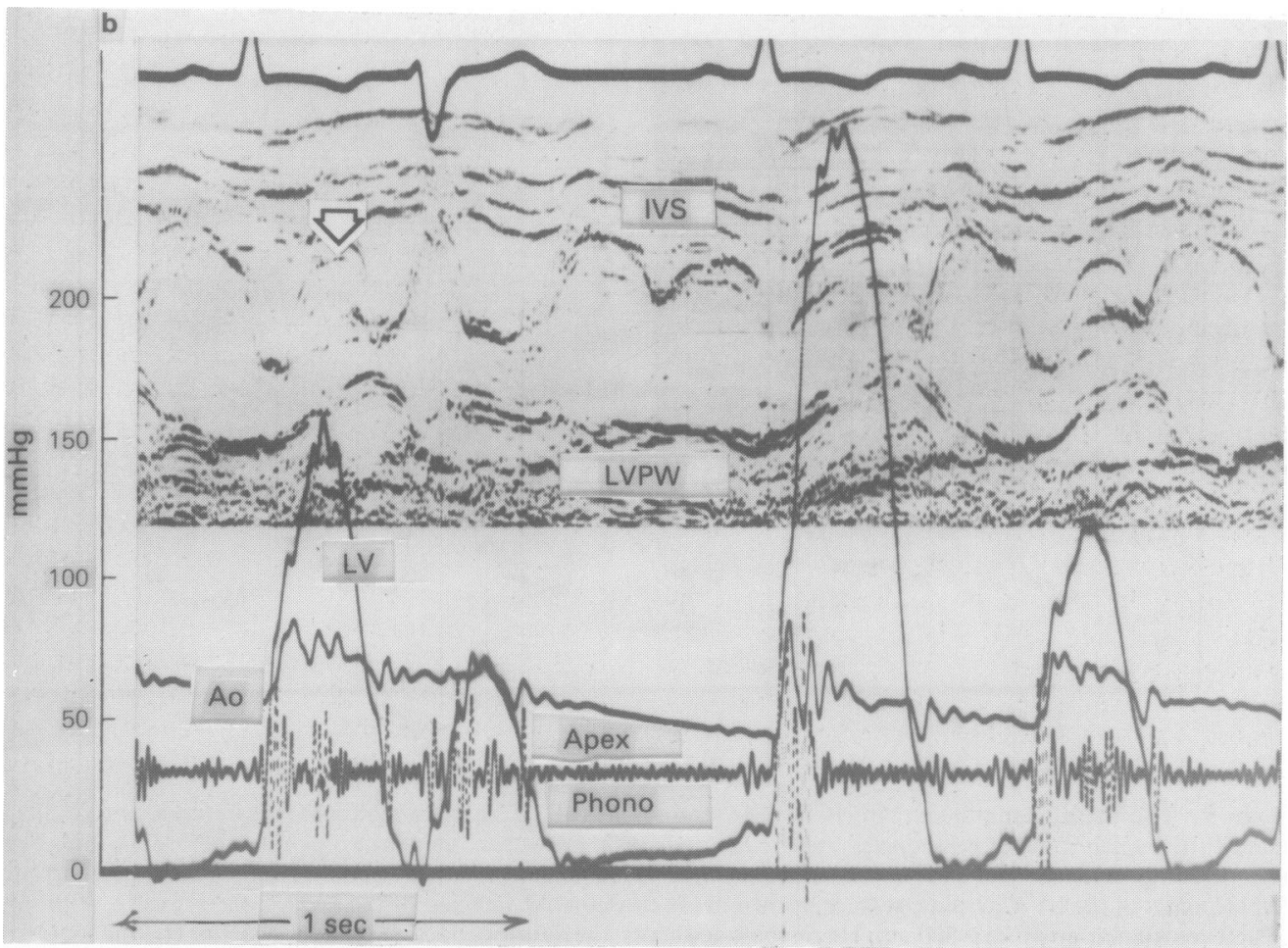

Figure 8 (b) A phono-echocardiogram recorded during the provocation of a premature ventricular contraction in a patient with HCM demonstrates a decrease in the murmur in the postextrasystolic beat in which a gradient of over $200 \mathrm{~mm} \mathrm{Hg}$ is recorded. (Reproduced with permission from Annals of Internal Medicine, 1986, 104, June issue.) 
c
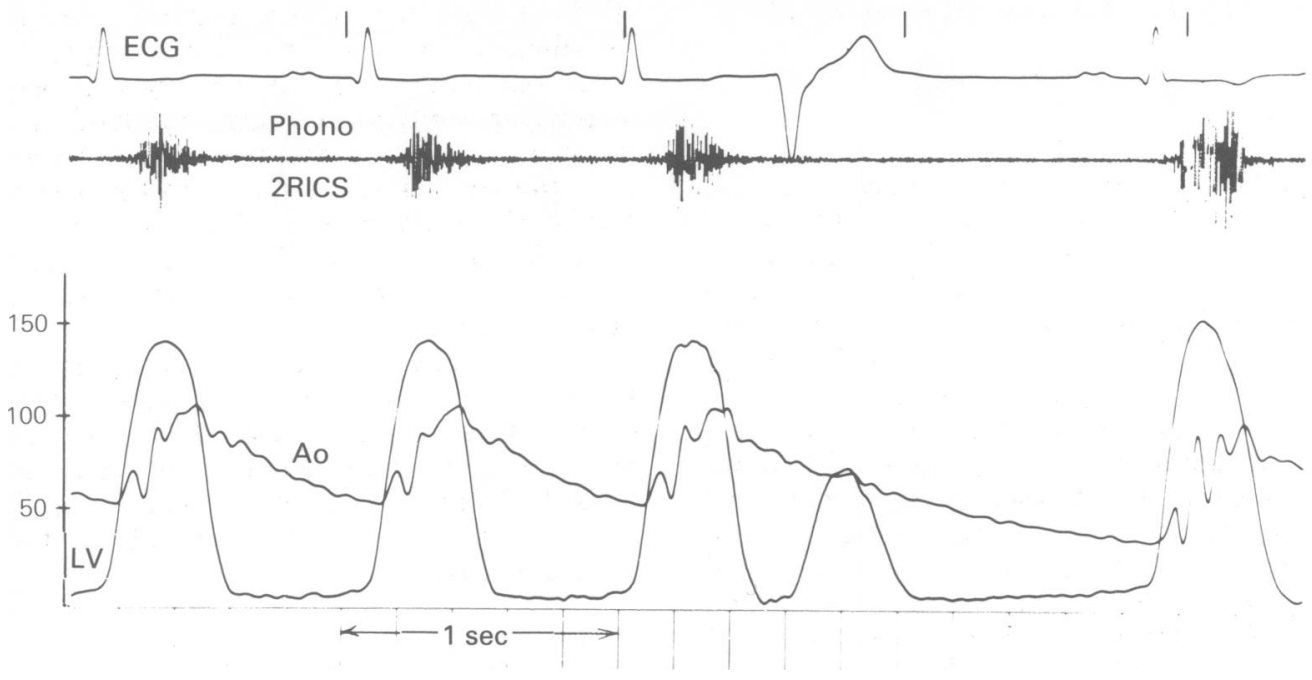

Figure 8 (c) In contrast a postextrasystolic augmentation of the pressure gradient and murmur are seen in a patient with valvar aortic stenosis. (Reproduced with permission from Annals of Internal Medicine, 1986, 104, June issue.)

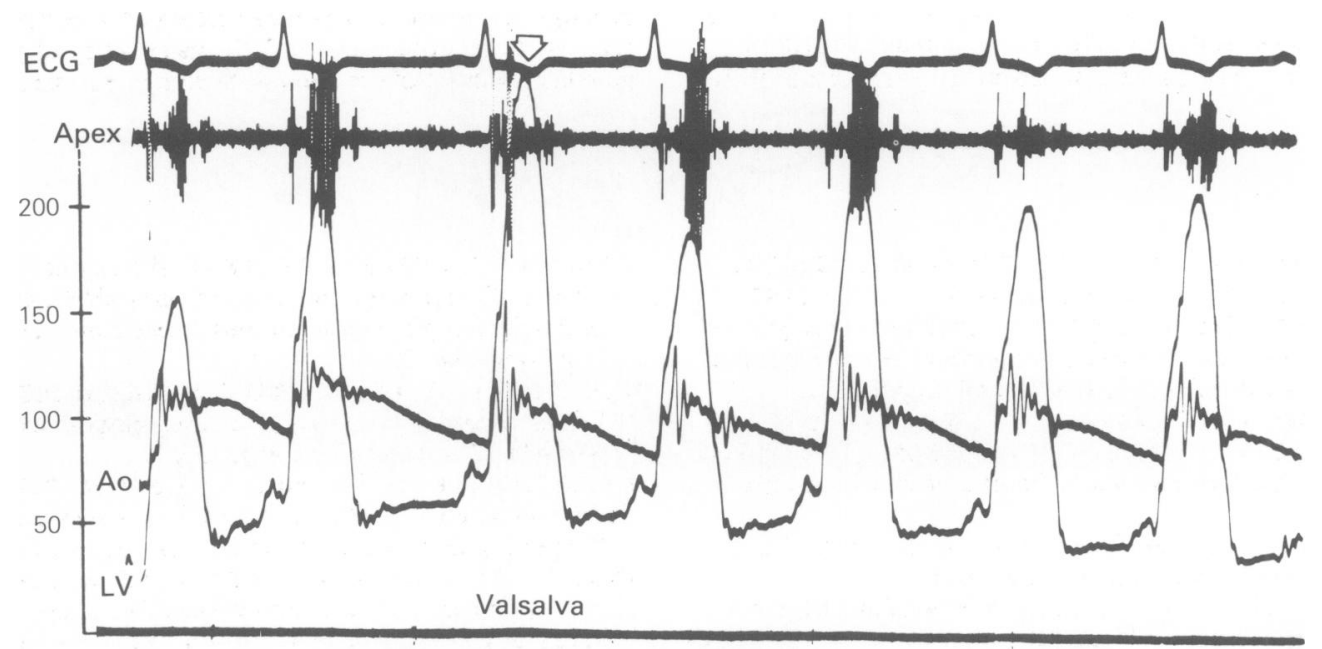

$1 \mathrm{sec} \longrightarrow$

Figure 9 The Valsalva manoeuvre in HCM. The strain phase of the Valsalva manoeuvre is initiated and results in an upward displacement of both the left ventricular and aortic pressures. A sinus pause occurs before the third beat, and the magnitude of the gradient increases, while the murmur intensity (arrow) diminishes. The upward displacement of the LV diastolic pressure by $50 \mathrm{~mm} \mathrm{Hg}$ causes a like increase of the LV systolic pressure. Although the left ventricular pressure is $200 \mathrm{~mm} \mathrm{Hg}$ on the last 4 beats, the developed $\mathrm{LV}$ pressure is $150 \mathrm{~mm} \mathrm{Hg}$, the same as it was before the onset of strain. The pressure gradient is larger during the Valsalva manoeuvre because of the fall in developed aortic pressure (aortic pressure minus intrathoracic pressure), which results from diminished LV filling. (Reproduced with permission from Annals of Internal Medicine, 1986, 104, June issue.) 
it can be seen in HCM in the absence of other manifestations of 'obstruction' (Kino et al., 1982).

\section{Conclusions}

It is noteworthy that at the midpoint of the first decade, a solid case had been developed for the presence of a 'contraction ring' which obstructed the outflow tract of the left ventricle. This 'contraction ring' had been demonstrable by angiocardiography, palpated by the surgeon, and its significance was demonstrable by recording a pressure gradient. However, the angiographic demonstration proved to be spurious; the diastolic configuration of the open mitral valve caused the conical or hourglass narrowing in the outflow tract. The surgeon's sphincter proved to be the obliterating cavity of the body of the left ventricle and the pressure gradient could be explained by the Gauer-Henry phenomenon (Criley et al., 1965; Gauer, 1950; Gauer \& Henry, 1964).

When the 'contraction ring' was no longer tenable, the 'obstruction' was translocated to the mitral valveseptal contact point, where it remains firmly entrenched today.

The fundamental differences remaining in the 'obstruction' controversy are whether or not the ventricle is impeded in its emptying, and whether or not the pressure gradient is of prime importance in the pathophysiology of HCM. The 'obstructive' argument holds that a localized anatomical narrowing of the

\section{References}

BORER, J.S., BACHARACH, S.L., GREEN, M.V., KENT, K.M., ROSING, D.R., SEIDES, S.F., MORROW, A.G. \& EPSTEIN, S.E. (1979). Effect of septal myotomy and myectomy on left ventricular systolic function at rest and during exercise in patients with IHSS. Circulation, 60 (Suppl I), 82.

BRAUNWALD, E., LAMBREW, C.T., MORROW, A.G., PIERCE, G.E., ROCKOFF, S.D. \& ROSS, J. JR. (1964). Idiopathic hypertrophic subaortic stenosis. Circulation, 30, IV-1.

BRISTOW, J.D. (1965). Recognition of left ventricular outflow obstruction. Circulation, 31, 600.

BROCK, R. (1957). Functional obstruction of the left ventricle (acquired aortic subvalvular stenosis). Guy's Hospital Reports, 106, 221.

BROCK, R. (1959). Functional obstruction of the left ventricle (acquired aortic subvalvular stenosis). Guy's Hospital Reports, 108, 126.

BROCKENBROUGH, E.C., BRAUNWALD, E. \& MORROW, A.G. (1961). A hemodynamic technic for the detection of hypertrophic subaortic stenosis. Circulation, 23, 189.

CANEDO, M.I., FRANK, M.J. \& ABDULLA, A.M. (1980). Rhythm disturbances in hypertrophic cardiomyopathy: prevalence, relation to symptoms and management. American Journal of Cardiology, 45, 848. outflow tract, caused by SAM-septal contact, impedes the emptying of the ventricle, and that removal of the impediment is a rational means of therapy.

On the other hand, the rapidity and degree of ventricular emptying belie the imposition of an impediment to outflow, and non-obstructive mechanisms can explain all of the phenomena classically attributed to 'obstruction'. Since substantial morbidity and mortality occur in the absence of a pressure gradient, the primacy of 'obstruction' in HCM should be questioned.

Until the cause of the pathological hypertrophy can be discovered and effectively reversed, treatment directed towards impaired diastolic relaxation (Lorell et al., 1982) and potentially life-threatening arrhythmias (McKenna et al., 1981; Frank et al., 1983a,b; McKenna et al., 1985), may prove to be the therapies of choice in HCM.

\section{Acknowledgements}

The authors would like to acknowledge the invaluable assistance of David Mickle in the fabrication of the hydrodynamic model depicted in Figure 7, and Drs Peter Ellis and Gerald Maurer in the pressure and continuous wave Doppler recordings. David Criley prepared the illustrations. Dr James P. Henry provided invaluable insights into the haemodynamic studies which he performed with the late Dr Otto H. Gauer which clarified the mechanism of pressure gradients without obstruction in hyperdynamic ventricles.

CANEDO, M.I. \& FRANK, M.J. (1981). Therapy of hypertrophic cardiomyopathy: medical or surgical? Clinical and pathophysiologic considerations. American Journal of Cardiology, 48, 383.

COOLEY, D.A., LEACHMAN, R.D. \& WUKASCH, D.C. (1973). Diffuse muscular subaortic stenosis: surgical treatment. American Journal of Cardiology, 31, 1.

CRILEY, J.M., LEWIS, K.B., WHITE, R.I. \& ROSS, R.S. (1965). Pressure gradients without obstruction. A new concept of "hypertrophic subaortic stenosis". Circulation, 32, 881.

CRILEY, J.M., LENNON, P.A., ABBASI, A.S. \& BLAUFUSS, A.H. (1976). In Clinical Cardiovascular Physiology, Levine, H.J. (ed).) p. 771. Grune \& Stratton Inc: New York.

CRILEY, J.M. (1979). The bottom line syndrome - hypertrophic cardiomyopathy revisited (Editorial Comment). Western Journal of Medicine, 130, 350.

DINSMORE, R.E., SANDERS, C.A. \& HARTHORNE, J.W. (1966). Mitral regurgitation in idiopathic hypertrophic subaortic stenosis. New England Journal of Medicine, 275, 1225.

DOBELL, A.R.C. \& SCOTT, H.J. (1964). Hypertrophic subaortic stenosis: evolution of a surgical technique. Journal of Thoracic and Cardiovascular Surgery, 47 (Suppl 1), 26. FEIZI, O. \& EMANUEL, R. (1975). Echocardiographic spec- 
trum of hypertrophic cardiomyopathy. British Heart Journal, 37, 1286.

FRANK, S. \& BRAUNWALD, E. (1968). Idiopathic hypertrophic subaortic stenosis: clinical analysis of 126 patients with emphasis on the natural history. Circulation, 37, 759.

FRANK, M.J., ABDULLA, A.M., WATKINS, L.O., PRISANT, L. \& STEFADOUROS, M.A. (1983a). Long-term medical management of hypertrophic cardiomyopathy: usefulness of propranolol. European Heart Journal, 4 (Suppl F), 155.

FRANK, M.J., STEFADOUROS, M.A., WATKINS, L.O., PRISANT, L.M. \& ABDULLA, A.M. (1983b). Rhythm disturbances in hypertrophic cardiomyopathy: relationship to symptoms and the effect of 'complete' beta blockade. European Heart Journal, 4 (Suppl F), 235.

GAUER, O.H. (1950). Evidence in circulatory shock of an isometric phase of ventricular contraction following ejection (abstr.). Federation Proceedings, 9, 47.

GAUER, O.H. \& HENRY, J.P. (1964). Negative (-Gz) acceleration in relation to arterial oxygen saturation, subendocardial hemorrhage and venous pressure in the forehead. Aerospace Medicine, 35, 533.

GINZTON, L.E. \& CRILEY, J.M. (1981). “Obstructive” systolic anterior motion of the mitral valve in cavity obliteration (abstr). Circulation, 64, IV-30.

GOODWIN, J.F. (1982). The frontiers of cardiomyopathy. British Heart Journal, 48, 1.

GOTSMAN, M.S. \& LEWIS, B.S. (1974). Left ventricular volumes and compliance in hypertrophic cardiomyopathy. Chest, 66, 498.

HENRY, W.L., CLARK, C.E., GLANCY, D.L. \& EPSTEIN, S.E. (1973). Echocardiographic measurement of the left ventricular outflow gradient in idiopathic hypertrophic subaortic stenosis. New England Journal of Medicine, 288, 989.

JULIAN, O.C., DYE, W.S., JAVID, H., HUNTER, J.A., MUENSTER, J.J. JR. \& NAJAFI, H. (1965). Apical left ventriculotomy in subaortic stenosis due to a fibromuscular hypertrophy. Circulation, 31 (Suppl 1), 44.

KINO, M., HIROTA, Y., KAKU, K., NAKAYAMA, Y., SUWA, M., DOI, Y. \& KAWAMURA, K. (1982). Midsystolic closure of the aortic valve in hypertrophic nonobstructive cardiomyopathy. Journal of Cardiography, 12, 319.

KRAMER, D.S., FRENCH, W.J. \& CRILEY, J.M. (1986. The postextrasystolic murmur response to gradient in hypertrophic cardiomyopathy. Annals of Internal Medicine, 102, in press.

KRIKLER, D.M., DAVIES, M.J., ROWLAND, E., GOODWIN, J.F., EVANS, R.C. \& SHAW, D.B. (1980). Sudden death in hypertrophic cardiomyopathy: Associated accessor atrioventricular pathways. British Heart Journal, 43, 245.

LORELL, B.H., PAULUS, W.J., GROSSMAN, W., WYNNE, J. \& COHN, P.F. (1982). Modification of abnormal left ventricular diastolic properties by nifedipine in patients with hypertrophic cardiomyopathy. Circulation, 65, 499.

MARON, B.J., SAVAGE, D.D., WOLFSON, J.K. \& EPSTEIN, S.E. (1981). Prognostic significance of 24 hour ambulatory electrocardiographic monitoring in patients with hypertrophic cardiomyopathy: a prospective study. American Journal of Cardiology, 48, 252.

MARON, B.J., EPSTEIN, S.E. \& MORROW, A.G. (1983). Symptomatic status and prognosis of patients after operation for hypertrophic obstructive cardiomyopathy: efficacy of ventricular septal myotomy and myectomy.
European Heart Journal, 4 (Suppl F), 175.

McKENNA, W.J., ENGLAND, D., DOI, Y.L., DEANFIELD, J.E., OAKLEY, C.M. \& GOODWIN, J.F. (1981a). Arrhythmia in hypertrophic cardiomyopathy: I. Influence on prognosis. British Heart Journal, 46, 168.

McKENNA, W.J., HARRIS, L., PEREZ, G., KRIKLER, D.M OAKLEY, C.M. \& GOODWIN, J.F. (1981b). Arrhythmia in hypertrophic cardiomyopathy: II. Comparison of amiodarone and verapamil in treatment. British Heart Journal, 46, 173.

MCKENNA, W.J., OAKLEY, C.M., KRIKLER, D.M. \& GOODWIN, J.F. (1985). Improved survival with amiodarone in patients with hypertrophic cardiomyopathy and ventricular tachycardia. British Heart Journal, 53, 412.

MORROW, A.G., REITZ, B.A., EPSTEIN, S.E., HENRY, W.L., CONKLE, D.M., ITSCOITZ, S.B. \& REDWOOD, D.R. (1975) Operative treatment in hypertrophic subaortic stenosis Techniques and the results of pre- and postoperative assessment in 83 patients. Circulation, 52, 88 .

MURGO, J.P., ALTER, B.R., DORETHY, J.F., ALTOBELLI, S.A \& McGRANAHAN, G.M. JR. (1980). Dynamics of left ventricular ejection in obstructive and nonobstructive hypertrophic cardiomyopathy. Journal of Clinical Investigation, 66, 1369.

MURGO, J.P. (1982). Does outflow obstruction exist in hypertrophic cardiomyopathy? New England Journal of Medicine, 307, 1008.

NISHIMURA, R.A., GIULIANI, E.R. \& BRANDENBURG, R.O (1983). Hypertrophic cardiomyopathy. Cardiovascular $R e-$ views and Reports, 4, 931.

POLLICK, C., MORGAN, C.D., GILBERT, B.W., RAKOWSK解 H. \& WIGLE, E.D. (1982). Muscular subaortic stenosis: The temporal relationship between systolic anterior motion of the anterior mitral leaflet and the pressure gradient? Circulation, 66, 1087.

POLLICK, C., RAKOWSKI, H. \& WIGLE, E.D. (1984). Muscular subaortic stenosis: the quantitative relationship between systolic anterior motion and the pressure gradient. Circulation, 69, 43.

RACKLEY, C.E., WHALEN, R.E. \& MCINTOSH, H.D. (1966). Ventricular volume studies in a patient with hypertrophic subaortic stenosis. Circulation, 34, 579.

ROSS, J. JR, BRAUNWALD, E., GAULT, J.H., MASON, D.T. \& MORROW, A.G. (1966). The mechanism of the intraventricular pressure gradient in idiopathic hypertrophic subaortic stenosis. Circulation, 34, 558.

ROTHLIN, M.E., GOBET, D., HABERER, T., KRAYENBUEHL, H.P., TURINA, M. \& SENNING, A. (1983). Surgical treatment versus medical treatment in hypertrophic obstructive cardiomyopathy. European Heart Journal, 4 (Suppl F), 215.

SAHN, D., BARRATT-BOYES, B., GRAHAM, K., HILL, D. \& KERR, A. (1982). Clarification of the site of "mitral septal apposition" in idiopathic hypertrophic subaortic stenosis (IHSS) by intra-operative two-dimensional (2D) echocardiography. (Abst.). American Journal of Cardiology, 49, 1009.

SANDERSON, J.E., GIBSON, D.G. \& GOODWIN, J.F. (1977). Left ventricular filling in hypertrophic cardiomyopathy. An echocardiographic study. British Heart Journal, 39, 661.

SAVAGE, D.D., SEIDES, S.F., MARON, B.J., MYERS, D.J. \& EPSTEIN, S.E. (1979). Prevalence of arrhythmias during 24 
hour electrocardiographic monitoring and exercise testing in patients with obstructive and non-obstructive hypertrophic cardiomyopathy. Circulation, 59, 866.

SHABETAI, R. (1984). Cardiomyopathy: How far have we come in 25 years, how far yet to go? Journal of the American College of Cardiology, 1, 252.

SHAH, P.M., GRAMIAK, C.E. \& KRAMER, D.H. (1969). Ultrasound localization of left ventricular outflow obstruction in hypertrophic obstructive cardiomyopathy. Circulation, 40, 3.

SIEGEL, R.J. \& CRILEY, J.M. (1985). A comparison of ventricular emptying with and without a pressure gradient in patients with hypertrophic cardiomyopathy. British Heart Journal, 53, 283.

SIMON, A.L., ROSS, J. JR. \& GAULT, J.H. (1967). Angiographic anatomy of the left ventricle and mitral valve in idiopathic hypertrophic subaortic stenosis. Circulation, 36, 852.

SUGRUE, D.D., McKENNA, W.J., DICKIE, S., MYERS, M.J., LAVENDER, J.P., OAKLEY, C.M. \& GOODWIN, J.F. (1984). The relation of left ventricular gradient and relative stroke volume ejected in early and late systole in hypertrophic cardiomyopathy: assessment with radionuclide cineangiography. British Heart Journal, 52, 602.

TEARE, D. (1958). Asymmetrical hypertrophy of the heart in young adults. British Heart Journal, 21, 1.

WHITE, R.I., CRILEY, J.M., LEWIS, K.B. \& ROSS, R.S. (1967).
Experimental production of intracavity pressure differences: possible significance in the interpretation of human hemodynamic studies. American Journal of Cardiology, 19, 806.

WIGLE, E.D., AUGER, P. \& MARQUIS, Y. (1966). Muscular subaortic stenosis. The initial left ventricular inflow tract pressure as evidence of outflow tract obstruction. Canadian Medical Association Journal, 95, 793.

WIGLE, E.D., MARQUIS, Y. \& AUGER, P. (1967). Muscular subaortic stenosis: initial left ventricular inflow tract pressure in the assessment of intraventricular pressure differences in man. Circulation, 35, 1100.

WILSON, W.S., CRILEY, J.M. \& ROSS, R.S. (1967). Dynamics of left ventricular emptying in hypertrophic subaortic stenosis: a cineangiographic and hemodynamic study. American Heart Journal, 73, 4.

WOLSTENHOLME, G.E.W. \& O'CONNOR, M. (eds). (1964). Cardiomyopathies, Ciba Foundation Symposium. Little, Brown \& Co.: Boston.

WYNNE, J. \& BRAUNWALD, E. (1984). Hypertrophic cardiomyopathy. In Heart Disease, Braunwald, E. (ed.) p. 1409. W.B. Saunders: Philadelphia. 